\title{
Efficacy and safety of high-dose long-acting repeatable octreotide as monotherapy or in combination with pegvisomant or cabergoline in patients with acromegaly not adequately controlled by conventional regimens: results of an open-label, multicentre study
}

\author{
Annamaria Colao ${ }^{1}$, Wojciech Zgliczyński ${ }^{2}$, Jan Komorowski ${ }^{3}$, Beata Kos-Kudła ${ }^{4}$, Antoine Tabarin ${ }^{5}$, \\ Veronique Kerlan $^{6}$, Francesco M. Minuto ${ }^{7}$, Carla Scaroni ${ }^{8}$, Marek Bolanowski ${ }^{9}$ \\ ${ }^{1}$ Department of Clinical Medicine and Surgery, Federico II University, Naples, Italy \\ ${ }^{2}$ Department of Endocrinology, Medical Centre of Postgraduate Education, Warsaw, Poland \\ ${ }^{3}$ Department of Clinical Endocrinology, Medical University of Lodz, Lodz, Poland \\ ${ }^{4}$ Department of Endocrinology, Medical University of Silesia, Katowice, Poland \\ ${ }^{5}$ Department of Endocrinology, University Hospital, Bordeaux, France \\ ${ }^{6}$ Department of Endocrinology, Diabetes, and Metabolic Disorders, CHU Brest, Hôpital de la Cavale Blanche, Brest, France \\ ${ }^{7}$ Department of Internal Medicine, University of Genova, Genova, Italy \\ ${ }^{8}$ Endocrine Unit, Department of Medicine, University of Padua Medical School, Padova, Italy \\ ${ }^{9}$ Department of Endocrinology, Diabetes and Isotope Therapy, Medical University, Wroclaw, Poland
}

\begin{abstract}
Introduction: Long-acting repeatable (LAR) octreotide i.m. is a potent, synthetic somatostatin analogue (SSA) that requires less frequent dosing and offers quality of life $(\mathrm{QoL})$ benefits in acromegaly patients compared to its shorter-acting predecessor. This study investigated the efficacy and safety of high-dose Sandostatin ${ }^{\circledR} \mathrm{LAR}^{\circledR}$ as monotherapy or in combination with pegvisomant or cabergoline in acromegalic patients with pituitary adenomas following previous failure of conventional SSA treatment.

Material and methods: After three months of high-dose Sandostatin ${ }^{\circledast}$ LAR $^{\circledast}$ monotherapy $(40 \mathrm{mg})$, patients who achieved biochemical control $(n=7)$ continued to receive the same treatment for an additional four months, whereas uncontrolled patients were randomised to receive high-dose Sandostatin ${ }^{\circledast} \mathrm{LAR}^{\circledR}$ in combination with pegvisomant $(\mathrm{n}=31)$ or cabergoline $(\mathrm{n}=32)$. Outcomes included biochemical response at eight months, QoL, and safety.

Results: After three months, 3 of 68 (4.4\%) evaluable patients achieved a biochemical control (BC) as assessed by levels of growth hormone and insulin-like growth factor-1. At eight months, 4 of 67 (6.0\%) patients achieved BC, including one receiving monotherapy and three receiving Sandostatin ${ }^{\circledR} \mathrm{LAR}^{\circledR}$ plus cabergoline. Partial response rate, improvements in acromegaly signs and symptoms, and changes in QoL were similar for all three groups. All treatments were well tolerated with a slight excess of adverse events in the combination arms. There were no deaths or serious adverse events leading to treatment discontinuation.

Conclusion: These data demonstrate that high-dose Sandostatin ${ }^{\circledast} \mathrm{LAR}^{\circledast}$ as monotherapy or in combination with pegvisomant or cabergoline is a feasible salvage option in patients with pituitary adenomas not adequately controlled on conventional SSA regimens. (Endokrynol Pol 2019; 70 (4): 305-312)

Key words: octreotide LAR; acromegaly; pegvisomant; cabergoline; combination; monotherapy
\end{abstract}

\section{Introduction}

Acromegaly is a rare chronic disease with a multifaceted clinical presentation [1]. In at least $90 \%$ of patients, the disease is caused by excess growth hormone (GH) release due to a pituitary adenoma $[2,3]$. Patients typically present with excessive skeletal growth, soft tissue enlargement and disfigurement, and are at increased risk of cardiovascular death $[4,5]$. Treatment goals are removal of the tumour mass and control of $\mathrm{GH}$ secretion to reduce the patients' morbidity and mortality $[1,6,7]$.

Somatostatin analogues (SSA) are considered standard medical treatment of acromegaly for patients with a low probability of a surgical cure or as adjuvant treatment after surgery [6-8]. By targeting control of GH and insulin-like growth factor 1 (IGF-1) levels, SSA treatment leads to improvements of the clinical signs and 
symptoms related to GH and IGF-1 excess, and tumour shrinkage [8]. This latter effect is particularly prominent in the first-line treatment of large macroadenomas but is also observed in patients with microadenomas $[2,8]$. Slow-release SSAs and long-acting dopamine agonists, such as cabergoline, provide effective and well-tolerated treatment for patients with poor response to previously available compounds, such as octreotide [9]. In patients with insufficient response to SSA monotherapy, combination therapy with dopamine agonists and selective $\mathrm{GH}$ receptor antagonists is effective at achieving disease control $[7,10]$.

Long-acting repeatable octreotide (Sandostatin ${ }^{\circledR}$ $\mathrm{LAR}^{\circledR}$ ) is a potent, synthetic SSA that offers the advantages of less frequent dosing and quality of life benefits with equivalent efficacy and tolerability in acromegaly patients compared to its shorter-acting predecessor [11, 12]. The objective of the present study was to investigate the efficacy and safety of high-dose Sandostatin ${ }^{\circledR}$ $\mathrm{LAR}^{\circledR}$ as monotherapy or in combination with pegvisomant (GH-receptor antagonist) or cabergoline (dopamine agonist) in a large population of acromegalic patients with pituitary adenomas following previous failure of first-generation SSA as a conventional SSA treatment.

\section{Material and methods}

\section{Study design}

This was a multicentre, phase IV, non-comparative, longitudinal, two-step, open-label study of high-dose octreotide LAR (Sandostatin ${ }^{\circledast}$ LAR $^{\circledast}$ ) monotherapy or combination therapy with pegvisomant or cabergoline in patients with acromegaly inadequately controlled after at least six months of a conventional SSA regimen (Fig. 1). The study was undertaken at 19 sites in five European countries between September 2006 and November 2009. The study was carried out in accordance with the Institutional Review Boardapproved protocol and with the principles of Good Clinical Practice as described in ICH guidelines and the Declaration of Helsinki, and all patients provided written, informed consent.

During study phase 1, all patients were treated with high-dose Sandostatin ${ }^{\circledast}$ LAR $^{\circledast}(40 \mathrm{mg})$ monotherapy for three months. Thereafter, GH and IGF-1 levels were assessed by a central laboratory and patients were assigned to one of the following groups for an additional four months of treatment during study phase 2: controlled patients (defined as mean one-hour $\mathrm{GH} \leq 2.5 \mu \mathrm{g} / \mathrm{L}$ and IGF- 1 within the normal range adjusted for age and gender) continued to receive high-dose Sandostatin ${ }^{\circledast} \mathrm{LAR}^{\circledast}$ monotherapy; uncontrolled patients [(defined as mean one-hour GH $>2.5 \mu \mathrm{g} / \mathrm{L}$ or IGF-1 above the upper limit of normal (ULN)] were randomised to receive high-dose Sandostatin ${ }^{\circledast}$ LAR $^{\circledast}$ in combination with pegvisomant (arm A) or cabergoline (arm B).

\section{Patient eligibility criteria}

Eligible patients were aged 18 years and older with biochemically documented (defined as mean one-hour GH level $>2.5 \mu \mathrm{g} / \mathrm{L}$ and IGF-1 above age- and gender-adjusted ULN) active acromegaly that

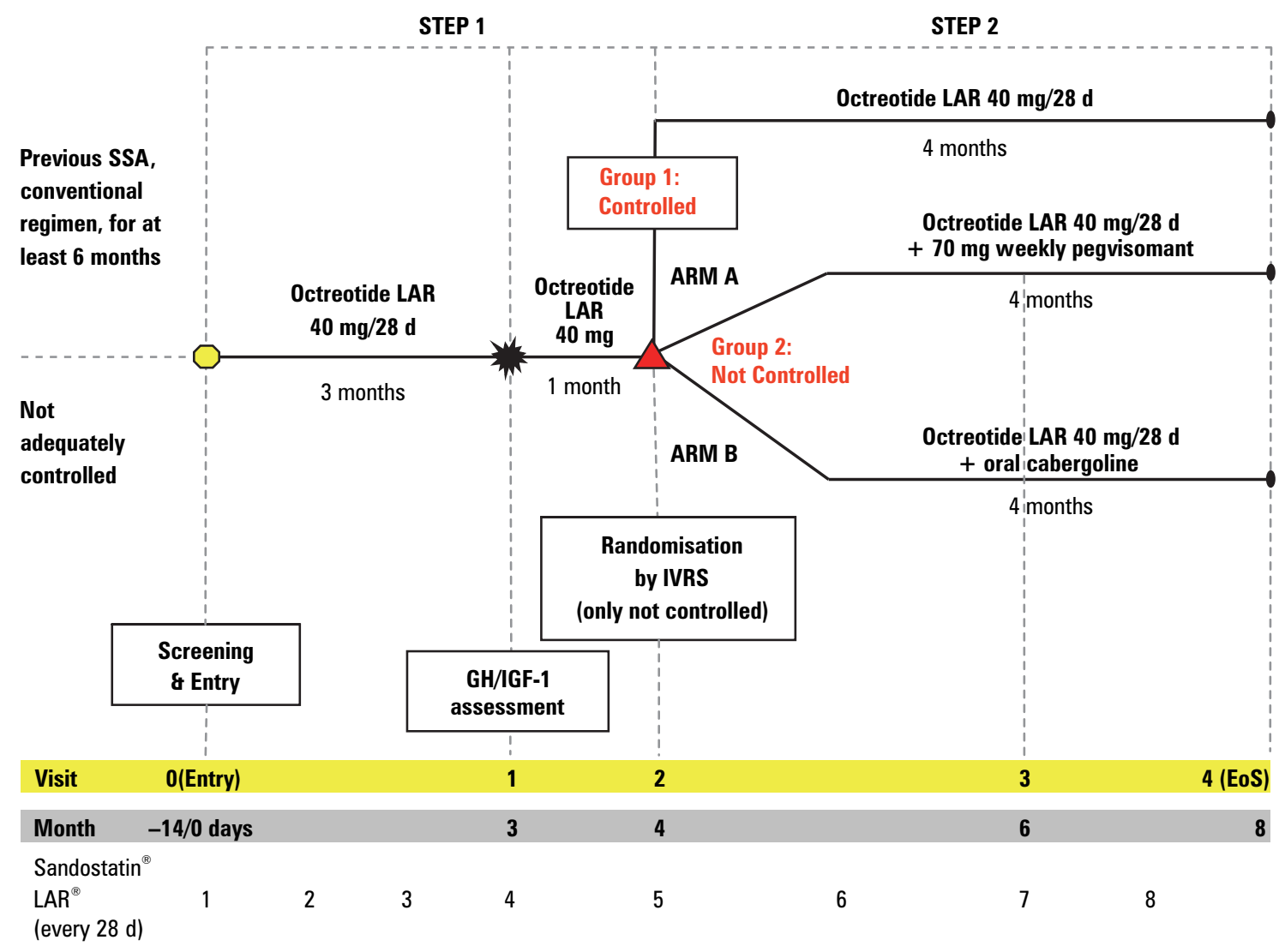

Figure 1. Study design. LAR — long-acting repeatable; SSA — synthetic somatostatin analogue; IVRS — interactive voice randomization system; GH - growth hormone; IGF-1 — insulin-like growth factor 1 
was not adequately controlled despite receiving conventional SSA treatment (defined as octreotide $30 \mathrm{mg}$ i.m. or lanreotide $120 \mathrm{mg}$ i.m. every 28 days) for at least six months. Additionally, patients were required to have a diagnosis of pituitary micro- or macroadenoma with no prior surgery and to show a reduction of either mean fasting $\mathrm{GH}$ of at least $50 \%$ or IGF-1 of at least $25 \%$ from any medical pretreatment level. Patients were excluded if they had newly diagnosed or untreated acromegaly; previous concomitant treatment with a GH receptor antagonist or a dopamine agonist unless the patien underwent a washout period of at least eight weeks or six weeks, respectively; symptomatic cholelithiasis or choledocholithiasis; liver transaminases at least three times the upper limit of normal; previous gamma-knife radiotherapy for treatment of acromegaly, with previous conventional radiotherapy only permitted if stopped at least three weeks prior to inclusion; compression of the optic chiasm causing a visual field defect; known hypersensitivity to any of the study drugs or to drugs with similar chemical structures; any medical conditions contraindicated in the Summary of Product Characteristics of all study drugs; or any current or prior medical condition that, in the judgment of the investigator, may interfere with the conduct of the study or evaluation of results. All patients had to provide written, informed consent.

\section{Treatment}

During phase 1 , all patients received Sandostatin ${ }^{\circledR}$ LAR $^{\circledR} 40 \mathrm{mg}$ i.m. every 28 days given as two divided doses $(20 \mathrm{mg} \times 2$ i.m. injections $)$ for three months. During phase 2, controlled patients continued to receive Sandostatin ${ }^{\circledR}$ LAR $^{\circledR} 40 \mathrm{mg}$ i.m. every 28 days for an additional four months, while uncontrolled patients also received either pegvisomant (arm A) $70 \mathrm{mg}$ subcutaneous (s.c.) weekly for four months or cabergoline (arm B) $0.25 \mathrm{mg}$ twice weekly $\left(1^{\text {st }}\right.$ week) $0.5 \mathrm{mg}$ twice weekly ( $2^{\text {nd }}$ week); $0.5 \mathrm{mg}$ four times weekly ( $3^{\text {rd }}$ week); and $0.5 \mathrm{mg}$ daily ( $4^{\text {th }}$ week and subsequent three months).

\section{Study endpoints}

The primary endpoint was the biochemical control (BC) rate at eight months (i.e. study end). Secondary endpoints were the $\mathrm{BC}$ rate at three months (i.e. end of part 1 ) and partial control (PC) rate at eight months; improvements from baseline in nine acromegaly-related clinical signs and symptoms, and health-related quality of life; and safety and tolerability of the administered treatments.

\section{Outcome measures}

$\mathrm{BC}$ was defined as mean one-hour $\mathrm{GH} \leq 2.5 \mu \mathrm{g} / \mathrm{L}$ and IGF-1 within the normal range adjusted for age and gender. PC was defined as mean one-hour $\mathrm{GH}>2.5 \mu \mathrm{g} / \mathrm{L}$ to $<5 \mu \mathrm{g} / \mathrm{L}$ and either $\geq 50 \%$ decrease in IGF-1 compared with baseline or IGF-1 within the normal range, or mean one-hour $\mathrm{GH}<2.5 \mu \mathrm{g} / \mathrm{L}$ and $\geq 50 \%$ decrease in IGF-1 compared with baseline and IGF-1 $>1 \times$ ULN. Acromegaly-related clinical signs and symptoms were scored on a four-point scale, and the average of all nine items was calculated. The total score was considered missing if three or more items were absent. HRQOL was assessed using the Acromegaly Quality of Life (AcroQoL) questionnaire - a self-administered questionnaire consisting of 22 items scored on a five-point Likert scale, with a higher score indicating better quality of life [13]. Safety assessments included physical examination, vital sign measurement, biochemistry, liver and gallbladder ultrasound, and adverse event (AE) reporting. AEs were coded using MedDRA version 12.0.

\section{Statistical analyses}

This was an exploratory study and all statistical analyses were descriptive. No formal statistical hypothesis was tested and the planned sample size of up to 100 patients was not based on statistical considerations. Assessment of patient demographic data and the efficacy analyses were performed on the intent-to-treat (ITT) population, which included all patients for whom at least one post-baseline measurement of GH and IGF-1 was available. For
BC and PC at three and eight months, 95\% confidence intervals (CI) were calculated using the Clopper-Pearson method. For the acromegaly-related clinical signs and symptoms scale, a regression analysis of repeated measures using a mixed-effects model was performed to assess the difference between Sandostatin ${ }^{\circledR}$ LAR $^{\circledR} 40 \mathrm{mg}$ plus pegvisomant and Sandostatin ${ }^{\circledR}$ LAR $^{\circledR} 40 \mathrm{mg}$ plus cabergoline treatment regimens during study phase 2 . AcroQoL items, total scale and three subscale values, and changes from baseline were summarised according to treatment group. The safety analysis was performed on the Safety population, which included all patients who received any study drug.

\section{Results}

Patient disposition and baseline characteristics

Seventy patients were enrolled in the study and received high-dose Sandostatin ${ }^{\circledast}$ LAR $^{\circledast}$ monotherapy. Patients had a mean age of 48 years; most were female (54.3\%) and white $(80.0 \%)$, with a predominant diagnosis of macroadenoma (92.9\%) (Tab. I).

After three months of high-dose Sandostatin LAR monotherapy, seven patients showed controlled acromegaly and received high-dose Sandostatin ${ }^{\circledR} \operatorname{LAR}^{\circledR}$ monotherapy for an additional four months. Of the 63 patients who had uncontrolled disease, 31 were randomised to high-dose Sandostatin ${ }^{\circledR}$ LAR $^{\circledast}$ plus pegvisomant ( $\operatorname{arm} \mathrm{A})$ and 32 were randomised to high-dose Sandostatin ${ }^{\circledast}$ LAR $^{\circledast}$ plus cabergoline (arm B).

Five $(7.1 \%)$ patients discontinued the study - four in the Sandostatin ${ }^{\circledR}$ LAR $^{\circledR}$ monotherapy group (two administrative problems, one lost to follow-up, and one other), and one in arm A (adverse event). Patient demographics were similar across treatment groups, with the exception that median time since diagnosis was longer in patients in arm A compared with those in arm B and the Sandostatin ${ }^{\circledast}$ LAR $^{\circledast}$ monotherapy arm, and the pituitary adenoma was notably smaller in patients treated with Sandostatin ${ }^{\circledast} \mathrm{LAR}^{\circledast}$ monotherapy compared with patients treated with combination therapy. Overall, the majority of patients at baseline had moderate acromegalic growth.

\section{Treatment exposure}

Almost all patients completed the study in the combination therapy groups $(96.8 \%$ in arm A and $100 \%$ in arm B), whereas in the monotherapy group $42.9 \%$ of patients completed the study. Mean \pm standard deviation (SD) overall exposure to Sandostatin ${ }^{\circledast} \operatorname{LAR}^{\circledast}$ $40 \mathrm{mg}$ was $6.3 \pm 1.2$ months. However, because less than half of the monotherapy group completed the study, mean exposure was shorter in the monotherapy group ( $3.9 \pm 2.7$ months) compared to the two combination treatment groups (arm A: $6.5 \pm 0.6$ months; arm B: $6.6 \pm 0.3$ months). Patients in arm A received pegvisomant for a mean \pm SD of $14.7 \pm 2.5$ weeks, and patients in arm $B$ received cabergoline for a mean \pm SD of $16.2 \pm 0.5$ weeks. 
Table I. Patient demographics and baseline characteristics intent-to-treat (ITT) population

\begin{tabular}{|c|c|c|c|c|}
\hline & $\begin{array}{c}\text { Total } \\
(n=70)\end{array}$ & $\begin{array}{l}\text { Octreotide LAR* } \\
\quad(\mathrm{n}=7)\end{array}$ & $\begin{array}{c}\text { Octreotide LAR } \\
+ \text { pegvisomant } \\
(\operatorname{Arm} A)^{*}(n=31)\end{array}$ & $\begin{array}{c}\text { Octreotide LAR } \\
+ \text { cabergoline } \\
(\text { Arm B })^{*}(n=32)\end{array}$ \\
\hline Mean age, years (SD) & $48.1(10.9)$ & $57.9(7.7)$ & $44.6(10.5)$ & $49.3(10.5)$ \\
\hline Female, $\mathbf{n}(\%)$ & $38(54.3)$ & $3(42.9)$ & $17(54.8)$ & $18(56.3)$ \\
\hline \multicolumn{5}{|l|}{ Race, n (\%) } \\
\hline White & $56(80.0)$ & $2(28.6)$ & $27(87.1)$ & $27(84.4)$ \\
\hline Other & $10(14.3)$ & $2(28.6)$ & $4(12.9)$ & $4(12.5)$ \\
\hline Missing & $4(5.7)$ & $3(42.9)$ & 0 & $1(3.1)$ \\
\hline Mean height [cm] (SD) & $170.8(10.4)$ & $169.4(11.0)$ & $172.7(11.6)$ & $169.3(9.0)$ \\
\hline Mean weight [kg] (SD) & $83.4(18.5)$ & $86.0(18.8)$ & $85.3(21.2)$ & $80.9(15.7)$ \\
\hline \multicolumn{5}{|l|}{ Diagnosis, n (\%) } \\
\hline Microadenoma & $5(7.1)$ & $2(28.6)$ & $2(6.5)$ & $1(3.1)$ \\
\hline Macroadenoma & $65(92.9)$ & $5(71.4)$ & $29(93.5)$ & 31 (96.9) \\
\hline Mean dimension of pituitary adenoma, mm (SD) & $23.7(12.0)$ & $15.3(8.7)$ & $26.7(14.2)$ & $23.0(9.4)$ \\
\hline \multicolumn{5}{|l|}{ Acromegalic growth, $\mathbf{n}(\%)$} \\
\hline Absent & $17(24.3)$ & $2(28.6)$ & $9(29.0)$ & $6(18.8)$ \\
\hline Mild & $14(20.0)$ & $1(14.3)$ & $2(6.5)$ & $11(34.4)$ \\
\hline Moderate & $30(42.9)$ & $2(28.6)$ & $16(51.6)$ & $12(37.5)$ \\
\hline Severe but not incapacitating & $8(11.4)$ & $1(14.3)$ & $4(12.9)$ & $3(9.4)$ \\
\hline Severe and incapacitating & $1(1.4)$ & $1(14.3)$ & 0 & 0 \\
\hline Median time since diagnosis, months (range) & $37.0(9-300)$ & $32.0(10-240)$ & $47.0(9-300)$ & $36.5(11-290)$ \\
\hline
\end{tabular}

*Patient demographics and baseline characteristics according to treatment assignment after 3 months of high-dose octreotide LAR monotherapy. One patient randomised to Arm B incorrectly received treatment as assigned to Arm A. LAR — long-acting repeatable; SD — standard deviation

\section{Biochemical response to treatment}

The overall $\mathrm{BC}$ rate at three months was $4.4 \%$, with three out of 68 evaluable patients achieving a BC. Based on the intention to treat, the $\mathrm{BC}$ rate at eight months in the overall patient population was $6.0 \%$, with 4 of 67 patients achieving a BC (Tab. II). A BC was observed in one of four $(25 \%)$ patients in the high-dose Sandostatin ${ }^{\circledR}$ LAR ${ }^{\circledast}$ monotherapy group, 3 of $32(9.4 \%)$ patients in arm $\mathrm{B}$, and no patients in arm $\mathrm{A}$. There was no significant difference between groups in the number of patients achieving BC. Across all treatments, 15 of $67(22.4 \%)$ patients achieved a PC at eight months, with a similar percentage of patients achieving this level of response in each of the treatment groups (Tab. II). The data for the monotherapy group should be interpreted with caution due to the small number of patients in this group.

Compared with baseline, GH levels decreased by a median of $-0.70 \mu \mathrm{g} / \mathrm{L}$ and $-1.30 \mu \mathrm{g} / \mathrm{L}$ at three and eight

Table II. Biochemical response at 8 months intent-to-treat (ITT) population

\begin{tabular}{|c|c|c|c|c|c|c|c|c|}
\hline & \multicolumn{2}{|c|}{$\begin{array}{c}\text { Total } \\
(\mathrm{n}=70)\end{array}$} & \multicolumn{2}{|c|}{$\begin{array}{l}\text { Octreotide LAR } \\
\qquad(\mathrm{n}=7)\end{array}$} & \multicolumn{2}{|c|}{$\begin{array}{c}\text { Octreotide LAR + } \\
\text { pegvisomant } \\
(\text { Arm } A)^{*}(n=31)\end{array}$} & \multicolumn{2}{|c|}{$\begin{array}{c}\text { Octreotide LAR + } \\
\text { cabergoline } \\
(\text { Arm B })^{*}(n=32)\end{array}$} \\
\hline & n (\%) & $95 \% \mathrm{Cl}$ & n (\%) & $95 \% \mathrm{CI}$ & n (\%) & $95 \% \mathrm{CI}$ & n (\%) & $95 \% \mathrm{Cl}$ \\
\hline Total evaluable $^{\dagger}$ & $67(100)$ & & $4(100)$ & & $31(100)$ & & $32(100)$ & \\
\hline $\mathrm{BC}$ & $4(6.0)$ & $1.7,14.6$ & $1(25.0)$ & $0.6,80.6$ & 0 & $0.0,11.2$ & $3(9.4)$ & $2.0,25.0$ \\
\hline No BC & $63(94.0)$ & & $3(75.0)$ & & $31(100)$ & & $29(90.6)$ & \\
\hline $\mathrm{PC}$ & $15(22.4)$ & $13.1,34.2$ & $1(25.0)$ & $0.6,80.6$ & $7(22.6)$ & $9.6,41.1$ & $7(21.9)$ & $9.3,40.0$ \\
\hline No PC & $52(77.6)$ & & $3(75.0)$ & & 24 (77.4) & & $25.0(78.1)$ & \\
\hline
\end{tabular}

${ }^{*}$ Biochemical response according to treatment assignment. One patient randomised to arm B incorrectly received treatment as assigned to arm $\mathrm{A}$; ${ }^{\dagger}$ Includes all patients with at least one post-baseline assessment of growth hormone and insulin-like growth factor-1; LAR — long-acting repeatable; BC — biochemical control;

$\mathrm{Cl}$ — confidence interval; $\mathrm{PC}$ - partial control. $\mathrm{p}>0.05$ for between-group comparisons 
months, respectively, in the overall patient population (Tab. III). The initial reduction on Sandostatin ${ }^{\circledast}$ LAR $^{\circledR}$ monotherapy was greater in patients who achieved biochemical disease control at three months and were subsequently assigned to continued Sandostatin ${ }^{\circledast} \mathrm{LAR}^{\circledast}$ monotherapy $(-2.70 \mu \mathrm{g} / \mathrm{L} v s .-0.50 \mu \mathrm{g} / \mathrm{L}$ and $-0.60 \mu \mathrm{g} / \mathrm{L}$ in patients assigned to arm $A$ and $B$, respectively). In patients randomised to high-dose Sandostatin ${ }^{\circledast}$ LAR $^{\circledast}$ plus pegvisomant, there was no change in $\mathrm{GH}$ level from three to eight months. However, initially uncontrolled patients who were randomised to Sandostatin ${ }^{\circledR}$ LAR $^{\circledR}$ plus cabergoline had further reduction in $\mathrm{GH}$ from -0.60 $\mu \mathrm{g} / \mathrm{L}$ at three months to $-1.70 \mu \mathrm{g} / \mathrm{L}$ at eight months. In contrast to GH levels, the levels of IGF-1 were universally lowered from three to eight months irrespective of treatment assignment (Tab. III). Reductions in IGF-1 at eight months were less marked in patients assigned to continue Sandostatin ${ }^{\circledast} \mathrm{LAR}^{\circledast}$ monotherapy $(-107 \mu \mathrm{g} / \mathrm{L})$ and in patients randomised to Sandostatin ${ }^{\circledast}$ LAR $^{\circledR}$ plus cabergoline $(-113 \mu \mathrm{g} / \mathrm{L})$, compared with patients who had received Sandostatin ${ }^{\circledast}$ LAR $^{\circledast}$ plus pegvisomant $(-252 \mu \mathrm{g} / \mathrm{L})$.

\section{Acromegaly-related clinical signs and symptoms}

At study end, moderate acromegalic growth and severe acromegalic growth were reported by one patient $(1.4 \%)$ each, with neither patient reporting symptoms of acromegalic growth at baseline. There were no significant trends indicating a difference in the shifts of acromegaly-related clinical signs and symptoms from baseline to end of study across the treatment groups. Repeated measures of analysis of acromegaly-related signs and symptoms similarly revealed no significant differences between arm A and arm B at six months [confidence interval (CI): $-0.15,0.17 ; \mathrm{p}=0.904)$ and eight months (CI: $-0.06,0.26 ; \mathrm{p}=0.218$ ).

\section{Acromegaly-related quality of life}

The mean change from baseline in the total AcroQoL score at four months was 11.36 for the high-dose Sandostatin ${ }^{\circledast} \mathrm{LAR}^{\circledast}$ monotherapy group compared with -0.39 and -2.16 in arm A and arm B, respectively. The mean change from baseline in the total AcroQoL score at eight months was comparable for the three treatment regimens ( 2.27 in the Sandostatin ${ }^{\circledast} \mathrm{LAR}^{\circledast}$ monotherapy group, 1.24 in arm A, 2.58 in arm B). A similar pattern was observed for mean subscale score, with small changes in individual AcroQoL items that were comparable for all three regimens.

\section{Safety and tolerability}

Overall, 47 (67.1\%) patients reported a total of 109 AEs, with 44 events in $26(37.1 \%)$ patients considered to be study drug-related. More patients in the combination

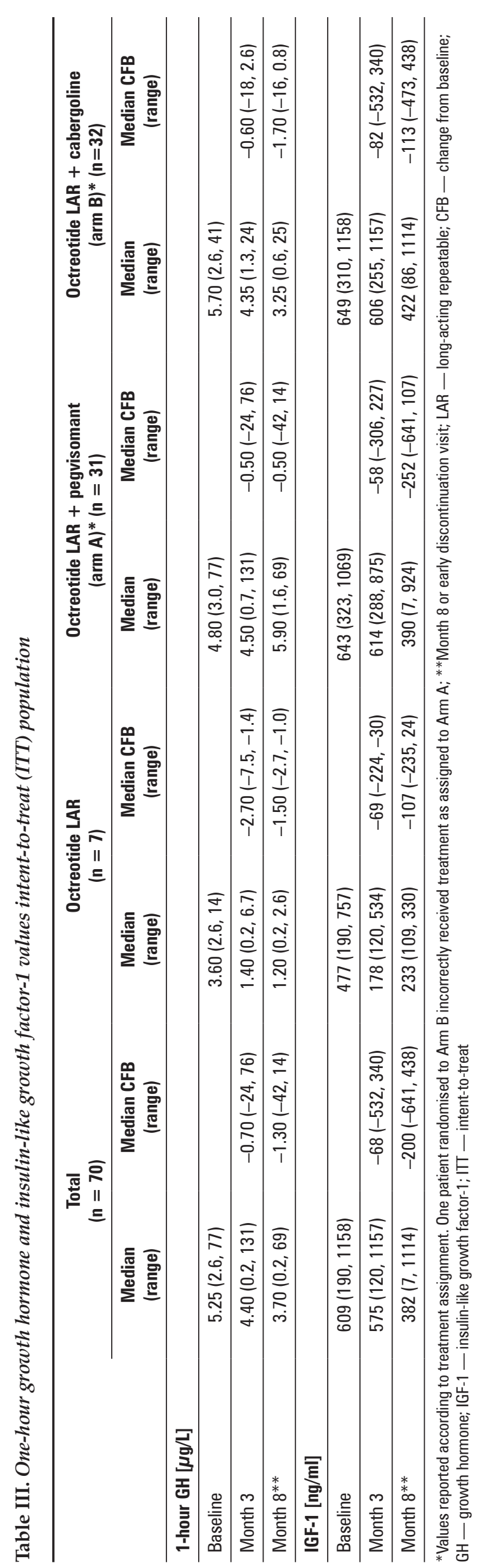


Table IV. Summary of adverse events (safety population)

\begin{tabular}{|c|c|c|c|}
\hline & $\begin{array}{l}\text { Octreotide LAR n (\%) } \\
(\mathrm{n}=7)\end{array}$ & $\begin{array}{l}\text { Octreotide LAR + pegvisomant } \\
(\operatorname{arm} A)^{*}, n(\%)(n=32)\end{array}$ & $\begin{array}{l}\text { Octreotide LAR + cabergoline } \\
(\operatorname{arm~B}) *, n(\%)(\mathrm{n}=31)\end{array}$ \\
\hline All adverse events & $4(57.1)$ & $21(65.6)$ & $22(71.0)$ \\
\hline $\begin{array}{l}\text { With suspected relationship } \\
\text { to study drug }\end{array}$ & $1(14.3)$ & $15(46.9)$ & $10(32.3)$ \\
\hline $\begin{array}{l}\text { Leading to dose adjustment } \\
\text { or temporary interruption }\end{array}$ & 0 & 0 & $2(6.5)$ \\
\hline Leading to permanent discontinuation & 0 & $1(3.1)$ & 0 \\
\hline $\begin{array}{l}\text { Requiring concomitant medication/ } \\
\text { /non-drug therapy }\end{array}$ & $1(14.3)$ & $13(40.6)$ & $13(41.9)$ \\
\hline Severe adverse events & 0 & $1(3.1)$ & $2(6.5)$ \\
\hline Resulting in death & 0 & 0 & 0 \\
\hline $\begin{array}{l}\text { With suspected relationship } \\
\text { to study drug }\end{array}$ & 0 & 0 & 0 \\
\hline Leading to permanent discontinuation & 0 & 0 & 0 \\
\hline \multicolumn{4}{|l|}{ System organ class ${ }^{\dagger}$ and preferred term } \\
\hline Infections and infestations & $2(28.6)$ & $6(18.8)$ & $6(19.4)$ \\
\hline Nasopharyngitis & $1(14.3)$ & $2(6.3)$ & $1(3.2)$ \\
\hline Gastrointestinal disorders & 0 & $7(21.9)$ & $6(19.4)$ \\
\hline Diarrhoea & 0 & $4(12.5)$ & $3(9.7)$ \\
\hline Abdominal pain & 0 & $2(6.3)$ & $3(9.7)$ \\
\hline $\begin{array}{l}\text { Musculoskeletal and connective } \\
\text { tissue disorders }\end{array}$ & 0 & $1(3.1)$ & $8(25.8)$ \\
\hline Back pain & 0 & $1(3.1)$ & $3(9.7)$ \\
\hline Nervous system disorders & $1(14.3)$ & $2(6.3)$ & $6(19.4)$ \\
\hline Headache & 0 & 0 & $4(12.9)$ \\
\hline Investigations & $1(14.3)$ & $6(18.8)$ & 0 \\
\hline Blood glucose increased & 0 & $4(12.5)$ & 0 \\
\hline $\begin{array}{l}\text { Respiratory, thoracic, } \\
\text { and mediastinal disorders }\end{array}$ & 0 & $2(6.3)$ & $4(12.9)$ \\
\hline Vascular disorders & 0 & $3(9.4)$ & $2(6.5)$ \\
\hline Eye disorders & 0 & $1(3.1)$ & $3(9.7)$ \\
\hline Metabolisms and nutrition disorders & 0 & $2(6.3)$ & $2(6.5)$ \\
\hline
\end{tabular}

${ }^{*}$ Adverse events according to treatment received. One patient randomised to arm B incorrectly received treatment as assigned to arm $A ;{ }^{\dagger}$ Adverse events by system organ class includes adverse events occurring in $\geq 5 \%$ of patients overall; LAR - long-acting repeatable

therapy arms than in the monotherapy group reported AEs with a suspected relationship to the study drug and required treatment with concomitant medication or non-drug therapy (Tab. IV). Three (4.3\%) patients overall experienced a serious $\mathrm{AE}$, none of which were considered to be related to treatment or resulted in discontinuation or death. The most commonly reported AEs by system organ class and preferred term are summarised in Table IV.

\section{Discussion}

Overall, low BC rates were observed in this multicentre, phase IV, non-comparative, longitudinal, two-step, open-label study investigating the efficacy and safety of high-dose octreotide LAR as monotherapy or in combination with pegvisomant or cabergoline in acromegaly patients. Across all treatment groups, 6.0\% of patients achieved BC after eight months, including one patient who received Sandostatin ${ }^{\circledR} \mathrm{LAR}^{\circledR}$ monotherapy and three patients who received high-dose Sandostatin ${ }^{\circledR}$ LAR $^{\circledR}$ plus cabergoline, whereas no BC was reported in the pegvisomant combination arm. Achievement of PC, improvement in acromegaly clinical signs and symptoms, and improvement in quality of life were similar across all treatment groups. All treatment groups showed an acceptable safety profile, although more patients receiving combination therapy reported AEs that were suspected to be treatment related. 
These results are in line with a study showing that octreotide LAR $60 \mathrm{mg}$ every 28 days was effective and well tolerated in patients with persistently uncontrolled acromegaly despite conventional SSA therapy. Ten out of 11 patients achieved IGF-1 reduction, and two of them presented normalisation of IGF-1 and GH levels after 24 weeks of therapy [14]. Another study showed that increasing octreotide LAR doses of up to $40 \mathrm{mg}$ every 28 days induced a further decrease of GH and IGF-1 levels in patients resistant to $30 \mathrm{mg}$ at the same injection interval, thus inducing disease control in $25 \%$ of them [15].

The current study also confirms that the addition of either pegvisomant or cabergoline to high-dose octreotide LAR represents a feasible treatment option in patients who are inadequately controlled on monotherapy. Pegvisomant functions as a selective GH receptor antagonist and blocks $\mathrm{GH}$ from binding to its receptor, resulting in decreased IGF-1 production [16]. However, as the mechanism of action blocks the effects of excessive GH instead of suppressing its secretion by the pituitary tumour, it is not possible to achieve biochemical control (both IGF-1 and GH normalisation) with pegvisomant. In the studies of pegvisomant in acromegaly patients, decreases in IGF-1 levels ranged from 27 to $63 \%[16,17]$. A recent long-term observational study showed IGF-1 normalisation in $73 \%$ of patients after 10 years of pegvisomant treatment [18].

In the current study, patients treated with Sandostatin ${ }^{\circledast}$ LAR $^{\circledast}$ plus pegvisomant experienced a mean decrease in IGF-1 levels of 39\% with little change in GH levels, which corresponded to achievement of PC in $23 \%$ of patients but no BCs. In contrast, patients treated with Sandostatin ${ }^{\circledast}$ LAR $^{\circledast}$ plus cabergoline experienced mean decreases in both GH and IGF-1 levels, resulting in a BC in $9 \%$ and $\mathrm{PC}$ in $22 \%$ of patients. These data are consistent with previous studies reporting mean decreases in IGF-1 levels ranging from 29 to $55 \%$ with adjunctive cabergoline in patients who were inadequately controlled with an SSA alone [19].

This study was limited by the small sample size of patients who received high-dose octreotide LAR monotherapy throughout the study; therefore, conclusions in these patients should be taken with caution.

The medical treatment approach to acromegaly is increasingly becoming individualised, taking into consideration the patient's tumour size and location, symptoms, comorbid conditions, and preferences [5,7]. In the case of SSAs, there are a number of factors that influence response, including gender, age, initial GH and IGF-1 levels, tumour mass, expression of somatostatin receptor types, and treatment duration and dose $[8,12]$. The combination of SSA with a different class of agent, such as a GH receptor antagonist or a dopamine agonist, is now regarded as a valid treatment approach when optimal biochemical control cannot be attained with long-acting SSA monotherapy $[7,10,20]$.

Nowadays, after completion of this study, a novel multi-somatostatin receptor ligand was introduced successfully in the treatment of acromegaly. Pasireotide reduces the tumour volume and achieves biochemical control or further significant suppression of the GH and IGF-I levels in a greater percentage of patients [21,22]. Combination therapy using pasireotide LAR together with pegvisomant was presented too. In a PAPE study, switching from first-generation SSA to pasireotide LAR, either as monotherapy or in combination with pegvisomant, could control IGF-1 levels in most patients, with an additional pegvisomant-sparing effect [23].

\section{Conclusions}

High-dose Sandostatin ${ }^{\circledast}$ LAR $^{\circledast}$ monotherapy achieved biochemical control in a small number of patients despite previous treatment failure, suggesting it is a viable salvage option in acromegalic patients with pituitary adenomas, who are inadequately controlled on conventional SSA regimens. Moreover, in the majority of patients who remained uncontrolled despite high-dose octreotide LAR, the adjunctive use of either pegvisomant or cabergoline was safe and well tolerated and may offer additional efficacy benefits compared to high-dose octreotide LAR alone.

\section{Acknowledgements}

This clinical trial (gov nr. NCT01278342) was supported by Novartis Pharma AG. Financial support for medical editorial assistance was provided by Novartis Pharma AG. We thank Marianne Eyholzer, PhD, TRM Oncology, The Hague, The Netherlands for her medical editorial assistance with this manuscript.

\section{References}

1. Katznelson L, Laws ER, Melmed S, et al. Endocrine Society. Acromegaly: an endocrine society clinical practice guideline. J Clin Endocrinol Metab. 2014; 99(11): 3933-3951, doi: 10.1210/jc.2014-2700, indexed in Pubmed: 25356808

2. Chanson P, Salenave S. Acromegaly. Orphanet J Rare Dis. 2008; 3: 17, doi: 10.1186/1750-1172-3-17, indexed in Pubmed: 18578866.

3. Melmed S. Acromegaly pathogenesis and treatment. J Clin Invest. 2009; 119(11): 3189-3202, doi: 10.1172/JCI39375, indexed in Pubmed: 19884662.

4. Melmed S, Casanueva FF, Klibanski A, et al. A consensus on the diagnosis and treatment of acromegaly complications. Pituitary. 2013; 16(3): 294-302, doi: 10.1007/s11102-012-0420-x, indexed in Pubmed: 2903574.

5. Bolanowski M, Ruchała M, Zgliczyński W, et al. Diagnostics and treatment of acromegaly - updated recommendations of the Polish Society of Endocrinology. Endokrynol Pol. 2019; 70(1): 2-18, doi: 10.5603/EP.a2018.0093, indexed in Pubmed: 30843181.

6. Fleseriu M. Clinical efficacy and safety results for dose escalation of somatostatin receptor ligands in patients with acromegaly: a literature review. Pituitary. 2011; 14(2): 184-193, doi: 10.1007/s11102-010-0282-z, indexed in Pubmed: 21161602

7. Melmed S, Bronstein MD, Chanson P, et al. A Consensus Statement on acromegaly therapeutic outcomes. Nat Rev Endocrinol. 2018; 14(9): 552-561, doi: 10.1038/s41574-018-0058-5, indexed in Pubmed: 30050156. 
8. Colao A, Auriemma RS, Lombardi G, et al. Resistance to somatostatin analogs in acromegaly. Endocr Rev. 2011; 32(2): 247-271, doi: 10.1210/er.2010-0002, indexed in Pubmed: 21123741.

9. Colao A, Lombardi G. Growth-hormone and prolactin excess. Lancet. 1998; 352(9138): 1455-1461, doi: 10.1016/S0140-6736(98)03356-X, indexed in Pubmed: 9808008.

10. Lim DS, Fleseriu M. The role of combination medical therapy in the treatment of acromegaly. Pituitary. 2017; 20(1): 136-148, doi: 10.1007/s11102-016-0737-y, indexed in Pubmed: 27522663.

11. Anthony L, Freda PU. From somatostatin to octreotide LAR: evolution of a somatostatin analogue. Curr Med Res Opin. 2009; 25(12): 2989-2999, doi: 10.1185/03007990903328959, indexed in Pubmed: 19842996.

12. Paragliola RM, Corsello SM, Salvatori R. Somatostatin receptor ligands in acromegaly: clinical response and factors predicting resistance. Pituitary. 2017; 20(1): 109-115, doi: 10.1007/s11102-016-0768-4, indexed in Pubmed: 27778296.

13. Badia X, Webb SM, Prieto L, et al. Acromegaly Quality of Life Questionnaire (AcroQoL). Health Qual Life Outcomes. 2004; 2: 13, doi: 10.1186/1477-7525-2-13, indexed in Pubmed: 14987332

14. Giustina A, Bonadonna S, Bugari G, et al. High-dose intramuscular octreotide in patients with acromegaly inadequately controlled on conventional somatostatin analogue therapy: a randomised controlled trial. Eur J Endocrinol. 2009; 161(2): 331-338, doi: 10.1530/EJE-09-0372, indexed in Pubmed: 19465485

15. Colao A, Pivonello R, Auriemma RS, et al. Beneficial effect of dose escalation of octreotide-LAR as first-line therapy in patients with acromegaly. Eur J Endocrinol. 2007; 157(5): 579-587, doi: 10.1530/EJE-07-0383, indexed in Pubmed: 17984237.

16. Trainer PJ, Drake WM, Katznelson L. Treatment of acromegaly with the growth hormone-receptor antagonist pegvisomant. N Engl J Med. 2000; 342(16): 1171-1177, doi: 10.1056/NEJM200004203421604, indexed in Pubmed: 10770982
17. Schreiber I, Buchfelder M, Droste M, et al. German Pegvisomant Investigators. Treatment of acromegaly with the GH receptor antagonist pegvisomant in clinical practice: safety and efficacy evaluation from the German Pegvisomant Observational Study. Eur J Endocrinol. 2007; 156(1): 75-82, doi: 10.1530/eje.1.02312, indexed in Pubmed: 17218728.

18. Buchfelder M, van der Lely AJ, Biller BMK, et al. Long-term treatment with pegvisomant: observations from 2090 acromegaly patients in ACROSTUDY. Eur J Endocrinol. 2018; 179(6): 419-427, doi: 10.1530/EJE-18-0616, indexed in Pubmed: 30325178.

19. Sandret L, Maison P, Chanson P. Place of cabergoline in acromegaly: a meta-analysis. J Clin Endocrinol Metab. 2011; 96(5): 1327-1335, doi: 10.1210/jc.2010-2443, indexed in Pubmed: 21325455.

20. Strasburger CJ, Mattsson A, Wilton P, et al. Increasing frequency of combination medical therapy in the treatment of acromegaly with the GH receptor antagonist pegvisomant. Eur J Endocrinol. 2018; 178(4): 321-329, doi: 10.1530/EJE-17-0996, indexed in Pubmed: 29371335.

21. Gadelha MR, Bronstein MD, Brue T, et al. Pasireotide C2402 Study Group. Pasireotide versus continued treatment with octreotide or lanreotide in patients with inadequately controlled acromegaly (PAOLA): a randomised, phase 3 trial. Lancet Diabetes Endocrinol. 2014; 2(11): 875-884, doi: 10.1016/S2213-8587(14)70169-X, indexed in Pubmed: 25260838 .

22. Shimon I, Adnan Z, Gorshtein A, et al. Efficacy and safety of long-acting pasireotide in patients with somatostatin-resistant acromegaly: a multicenter study. Endocrine. 2018; 62(2): 448-455 doi: 10.1007/s12020-018-1690-5, indexed in Pubmed: 30051198

23. Muhammad A, van der Lely AJ, Delhanty PJD. Efficacy and Safety of Switching to Pasireotide in Patients With Acromegaly Controlled With Pegvisomant and First-Generation Somatostatin Analogues (PAPE Study). J Clin Endocrinol Metab. 2018; 103(2): 586-595, doi: 10.1210/jc.2017-02017, indexed in Pubmed: 29155991. 